\title{
A single-source precursor route to anisotropic halogen-doped zinc oxide particles as a promising candidate for new transparent conducting oxide materials
}

\author{
Daniela Lehr ${ }^{1}$, Markus R. Wagner², Johanna Flock ${ }^{3}$, Julian S. Reparaz², \\ Clivia M. Sotomayor Torres ${ }^{2,4}$, Alexander Klaiber ${ }^{1}$, Thomas Dekorsy ${ }^{3}$ \\ and Sebastian Polarz ${ }^{* 1}$
}

\author{
Full Research Paper \\ Address: \\ ${ }^{1}$ Department of Chemistry, University of Konstanz, 78457 Konstanz, \\ Germany, ${ }^{2} \mathrm{ICN} 2$ Catalan Institute of Nanoscience and \\ Nanotechnology, Campus UAB, 08193 Bellaterra (Barcelona), Spain, \\ ${ }^{3}$ Department of Physics, University of Konstanz, 78457 Konstanz, \\ Germany and ${ }^{4}$ Catalan Institute of Research and Advanced Studies \\ (ICREA), Barcelona 08010, Spain \\ Email: \\ Sebastian Polarz* - sebastian.polarz@uni-konstanz.de \\ ${ }^{*}$ Corresponding author \\ Keywords: \\ chemical doping; metal oxides; semiconductor nanoparticles; \\ single-source precursors \\ Beilstein J. Nanotechnol. 2015, 6, 2161-2172. \\ doi:10.3762/bjnano.6.222 \\ Received: 30 July 2015 \\ Accepted: 02 November 2015 \\ Published: 18 November 2015 \\ Associate Editor: J. J. Schneider \\ (c) 2015 Lehr et al; licensee Beilstein-Institut. \\ License and terms: see end of document.
}

\footnotetext{
Abstract

Numerous applications in optoelectronics require electrically conducting materials with high optical transparency over the entire visible light range. A solid solution of indium oxide and substantial amounts of tin oxide for electronic doping (ITO) is currently the most prominent example for the class of so-called TCOs (transparent conducting oxides). Due to the limited, natural occurrence of indium and its steadily increasing price, it is highly desired to identify materials alternatives containing highly abundant chemical elements. The doping of other metal oxides (e.g., zinc oxide, $\mathrm{ZnO}$ ) is a promising approach, but two problems can be identified. Phase separation might occur at the required high concentration of the doping element, and for successful electronic modification it is mandatory that the introduced heteroelement occupies a defined position in the lattice of the host material. In the case of $\mathrm{ZnO}$, most attention has been attributed so far to $\mathrm{n}$-doping via substitution of $\mathrm{Zn}^{2+}$ by other metals (e.g., $\mathrm{Al}^{3+}$ ). Here, we present first steps towards n-doped $\mathrm{ZnO}$-based TCO materials via substitution in the anion lattice $\left(\mathrm{O}^{2-}\right.$ versus halogenides). A special approach is presented, using novel single-source precursors containing a potential excerpt of the target lattice ' $\mathrm{HalZn} \cdot \mathrm{Zn}_{3} \mathrm{O}_{3}$ ' preorganized on the molecular scale $(\mathrm{Hal}=\mathrm{I}, \mathrm{Br}, \mathrm{Cl})$. We report about the synthesis of the precursors, their transformation into halogene-containing $\mathrm{ZnO}$ materials, and finally structural, optical and electronic properties are investigated using a combination of techniques including FT-Raman, low- $T$ photoluminescence, impedance and $\mathrm{THz}$ spectroscopies.
} 


\section{Introduction}

There is an ever increasing demand for electrode materials exhibiting optical transparency in the visible region of the electromagnetic spectrum, because they are indispensable constituents in important technological devices such as flat panel displays, touch screens, solar cells and photocatalytic systems [1-4]. Among the different materials used for this purpose [5] such as carbon nanostructures [6-8], silver nanowires $[9,10]$ or conducting polymers [11], the so-called TCOs (transparent conducting oxides) have some favorable features such as high durability, chemical resistance, e.g., against oxygen, water or other atmospheric contaminants, and they show good mechanical stability $[1,12,13]$. Optical transparency is realized by selection of a wide-gap semiconductor material, and substantial chemical doping leads to a sufficient amount of mobile charge carriers. The best-known example for TCOs is indium tin oxide (ITO) [4]. ITO can be characterized as a tin-doped indium oxide material with up to $90 \%$ content of $\operatorname{In}_{2} \mathrm{O}_{3}$. It is characterized by a low specific resistivity of the order $\rho \approx 1 \times 10^{2} \mu \Omega \cdot \mathrm{cm}$. ITO is highly conductive, transparent in the visible and reflective in the IR spectral region [14]. Because indium is a rare element (with an abundancy of $\left(1.00 \times 10^{-5}\right) \%$ in the earth crust) [15], and due to the steadily growing need and price, there is a large demand for ITO substitutes [16].

TCOs consisting of chemically doped zinc oxide materials ('E@ZO'; E = heteroelement) have been recognized as promising candidates as ITO substitutes $[17,18]$. Because $\mathrm{ZnO}$ is already n-type in its native state, and due to the difficulties associated with p-doping [19,20], most attention was devoted to $\mathrm{n}$-doping via substitution in the cation $\left(\mathrm{Zn}^{2+}\right)$ lattice. The most prominent example known to date is aluminium-doped $\mathrm{ZnO}$ (AZO) [21,22]. AZO contains much more common elements compared to ITO, however, it cannot yet compete regarding its electrical properties. Much less work was invested in the preparation and investigation of $\mathrm{n}$-doped $\mathrm{ZnO}$ via substitution in the anion lattice, which can be realized by the introduction of halogens instead of oxygen. There are only few papers describing F-doped $\mathrm{ZnO}$ (FZO) [23-25] and almost nothing is known about $\mathrm{Cl} @ \mathrm{ZnO}$ [26-30], Br@ZnO and I@ZnO. This is because successful lattice substitution becomes more difficult, the larger the difference between the ionic radius of $\mathrm{Hal}^{-}\left(r\left(\mathrm{~F}^{-}\right)\right.$ $\left.=131 \mathrm{pm} ; r\left(\mathrm{Cl}^{-}\right)=181 \mathrm{pm} ; r\left(\mathrm{Br}^{-}\right)=196 \mathrm{pm}, r\left(\mathrm{I}^{-}\right)=220 \mathrm{pm}\right)$ and $\mathrm{O}^{2-}\left(r\left(\mathrm{O}^{2-}\right)=138 \mathrm{pm}\right)$ is.

Physical methods such as different variants of physical vapor deposition and sputtering have been proven to be a good technique for the preparation of thin films of $\mathrm{E} @ \mathrm{ZnO}$ on different substrates [31-34]. Despite some inherent advantages such as good crystallinity of the materials, some drawbacks of the mentioned physical methods are that they require quite demanding, high-vacuum equipment, correct process parameters are often difficult to find, and nanostructures different from thin films cannot be obtained. For the preparation of semiconductor nanomaterials such as colloidal particles, quantum dots or porous materials bottom-up synthesis routes in the liquid phase are commonly applied [35-37]. Whereas, bottom-up techniques such as the sol-gel process for metal oxides [38,39] work perfectly for the generation of an entire zoo of nanostructures, to realize at the same time intentional doping of those nanostructures is extremely demanding [40]. Often a desired heteroelement does not incorporate, e.g., due to different solubility in the used solvent or due to different reaction kinetics. It can be concluded, that there is currently an important deficiency between the potential of physical methods granting precisely doped semiconductors and the potential of bottom-up methods enabling control over materials morphology.

The mentioned problem could be solved, if one uses special molecules for materials synthesis. So-called molecular singlesource precursors (MSSPs) contain, on the molecular level, all required elements for the final material [41-43]. They are very reactive, guarantee a high mass transport and can be converted into the solid material at relatively low temperatures. Whereas a substantial number of MSSPs for binary materials are known, there are only few examples for ternary phases as targets [4446]. Our group has extensive experience with MSSPs for $\mathrm{ZnO}$ materials [47-49], and several examples for ternary phases (Mn@ZnO, Ni@ZnO, Cr@ZnO,Li@ZnO, S@ZnO) were reported [50-54]. The advantage of using MSSPs for ternary phases is, that kinetically controlled synthesis routes can be realized leading to very high substitution degrees, in some cases even above the solubility limit.

In the current contribution, we are seeking for a novel MSSP route towards Hal@ZnO materials. First, we will describe the synthesis and characterization of the molecular precursors. Then, their transformation into Hal@ZnO materials will be studied. Focusing on $\mathrm{Cl} @ \mathrm{ZnO}$, important optical and electronic properties will be investigated in detail.

\section{Experimental Synthesis}

All starting compounds were received from Aldrich, were purified and carefully dried prior to use. All reactions were performed under strict exclusion of air and humidity using Schlenk techniques. [MeZnOt-Bu $]_{4}$ and $[\mathrm{EtZnOiPr}]_{4}$ were synthesized according to the literature [55].

Preparation of $\left[\mathbf{I}\left(\mathrm{CH}_{3}\right)_{3} \mathbf{Z n}_{4}(\mathbf{O} t-B u)_{4}\right]$ (2a): In $60 \mathrm{~mL}$ toluene $4 \mathrm{~g}[\mathrm{MeZnO} t-\mathrm{Bu}] 4(6.51 \mathrm{mmol})$ were dissolved and cooled to 
$-78{ }^{\circ} \mathrm{C}$. A solution of $1.65 \mathrm{~g}$ dried $\mathrm{I}_{2}$ in $40 \mathrm{~mL}$ toluene was added drop-wise. The solution was warmed up to room temperature overnight under continuous stirring. The solvent was removed under reduced pressure. The residue was dissolved in $40 \mathrm{~mL}$ hexane and insoluble impurities were removed via centrifugation. The solvent was removed under reduced pressure and the product was obtained as a colorless solid (78\%). ${ }^{1} \mathrm{H}$ NMR $\left(400 \mathrm{MHz}, \mathrm{CDCl}_{3}\right) \delta-0.37\left(\mathrm{~s}, 1 \mathrm{H}, \mathrm{ZnCH}_{3}\right)$, $1.39\left(\mathrm{~s}, 1 \mathrm{H}, \mathrm{CH}_{3}\right), 1.48 \mathrm{ppm}\left(\mathrm{s}, 3 \mathrm{H}, \mathrm{CH}_{3}\right) ;{ }^{13} \mathrm{C} \mathrm{NMR}$

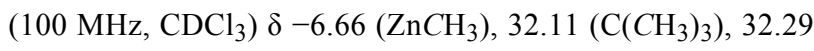
$\left(\mathrm{C}\left(\mathrm{CH}_{3}\right)_{3}\right), 75.15\left(\mathrm{C}\left(\mathrm{CH}_{3}\right)_{3}\right), 76.12\left(\mathrm{C}_{\left.\left(\mathrm{CH}_{3}\right)_{3}\right)}\right)$ MS (EI) $\mathrm{m} / \mathrm{z}$ : $M-\mathrm{CH}_{3}{ }^{+} 710.9$.

Preparation of $\left[\mathrm{Br}\left(\mathrm{CH}_{3}\right)_{3} \mathrm{Zn}_{4}(\mathrm{Ot} \text {-Bu })_{4}\right]$ (2b): In $60 \mathrm{~mL}$ hexane $3 \mathrm{~g}[\mathrm{MeZnO} t$-Bu]4 $(6.51 \mathrm{mmol})$ were dissolved and cooled to $-78{ }^{\circ} \mathrm{C} .4 .9 \mathrm{~mL}$ of $1 \mathrm{M} \mathrm{Br}_{2}$ solution in hexane were diluted with $18 \mathrm{~mL}$ hexane and added dropwise. The solution was warmed up to room temperature overnight under continuous stirring. Insoluble impurities were removed via centrifugation; the solvent was removed under reduced pressure and the product was obtained as a colorless solid $(52 \%)$. ${ }^{1} \mathrm{H}$ NMR $\left(400 \mathrm{MHz}, \mathrm{CDCl}_{3}\right) \delta-0.38\left(\mathrm{~s}, 1 \mathrm{H}, \mathrm{ZnCH}_{3}\right), 1.38\left(\mathrm{~s}, 1 \mathrm{H}, \mathrm{CH}_{3}\right)$, $1.45 \mathrm{ppm}\left(\mathrm{s}, 3 \mathrm{H}, \mathrm{CH}_{3}\right) ;{ }^{13} \mathrm{C} \mathrm{NMR}\left(100 \mathrm{MHz}, \mathrm{CDCl}_{3}\right) \delta-7.16$

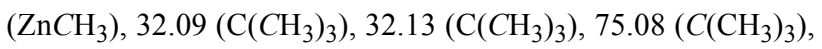
$75.88\left(\mathrm{C}\left(\mathrm{CH}_{3}\right)_{3}\right)$.

Preparation of $\left[\mathrm{ClEt}_{3} \mathrm{Zn}_{\mathbf{4}}(\mathrm{OiPr})_{\mathbf{4}}\right]$ (2c): $3.5 \mathrm{~g}$ [EtZnOiPr $]_{4}$ $(5.7 \mathrm{mmol})$ were dissolved in $70 \mathrm{~mL}$ toluene and cooled to $-78{ }^{\circ} \mathrm{C} .5 .7 \mathrm{~mL}$ of $1 \mathrm{M} \mathrm{HCl} \cdot \mathrm{Et}_{2} \mathrm{O}$ were diluted with $16 \mathrm{~mL}$ $\mathrm{Et}_{2} \mathrm{O}$ and added dropwise. The solution was warmed up to room temperature overnight under continuous stirring. Insoluble impurities were removed via centrifugation; the solvent was removed under reduced pressure. The colorless solid was recrystallized from hexane (56\%). ${ }^{1} \mathrm{H} \mathrm{NMR}\left(400 \mathrm{MHz}, \mathrm{CDCl}_{3}\right) \delta$ $0.37\left(\mathrm{q},{ }^{3} J=8.1 \mathrm{~Hz}, 6 \mathrm{H}, \mathrm{ZnCH}_{2} \mathrm{CH}_{3}\right), 1.26\left(\mathrm{t},{ }^{3} J=8.1 \mathrm{~Hz}, 9 \mathrm{H}\right.$, $\mathrm{ZnCH}_{2} \mathrm{CH}_{3}$ ), 1.30, 1.35 (each d, ${ }^{3} J=6.1 \mathrm{~Hz}$, altogether $24 \mathrm{H}$, $\mathrm{CH}_{3}$ ), 4.24, 4.17 (each h, ${ }^{3} \mathrm{~J}=6.1 \mathrm{~Hz}$, altogether $4 \mathrm{H}, \mathrm{CH}$ ) ppm; ${ }^{13} \mathrm{C} \mathrm{NMR}\left(100 \mathrm{MHz}, \mathrm{CDCl}_{3}\right) \delta 1.28\left(\mathrm{ZnCH}_{2} \mathrm{CH}_{3}\right), 12.20$ $\left(\mathrm{ZnCH}_{2} \mathrm{CH}_{3}\right), 27.05\left(\mathrm{CH}\left(\mathrm{CH}_{3}\right)_{2}\right), 27.14\left(\mathrm{CH}\left(\mathrm{CH}_{3}\right)_{2}\right), 69.29$ $\left(\mathrm{CH}\left(\mathrm{CH}_{3}\right)_{2}\right), 69.74\left(\mathrm{CH}\left(\mathrm{CH}_{3}\right)_{2}\right)$.

Preparation of Hal@ZnO: The single-source-precursor 2a, 2b or $\mathbf{2} \mathbf{c}$ is placed in a porcelain combustion boat and transferred into a tube oven (Nabertherm R50/500/12, equipped with a $2.7 \mathrm{~cm}$ diameter quartz tube). Under $\mathrm{N}_{2} / \mathrm{O}_{2}$ atmosphere $\left(0.05 \mathrm{~L} / \mathrm{min} \mathrm{N}_{2}, 0.2 \mathrm{~L} / \mathrm{min}_{2}\right)$ the oven was heated up (heating rate $2 \mathrm{~K} / \mathrm{min}$ ) to $350{ }^{\circ} \mathrm{C}$ and the temperature was kept for $10 \mathrm{~h}$.

Preparation of $\mathrm{ZnO}_{1-x} \mathbf{C l}_{x}$ with various doping levels: As an example $1.0 \mathrm{~g}$ [EtZnOiPr $]_{4}(1.63 \mathrm{mmol})$ and $0.088 \mathrm{~g}$
$\left[\mathrm{ClEt}_{3} \mathrm{Zn}_{4}(\mathrm{OiPr})_{4}\right](0.14 \mathrm{mmol})$ were dissolved in $20 \mathrm{~mL}$ THF. After stirring for $10 \mathrm{~min}$, the solvent was removed under reduced pressure. The precursor mixture was placed in a porcelain combustion boat and transferred into a tube oven (Nabertherm R50/500/12, equipped with a $2.7 \mathrm{~cm}$ diameter quartz tube). Under $\mathrm{N}_{2} / \mathrm{O}_{2}$ atmosphere $\left(0.05 \mathrm{~L} / \mathrm{min} \mathrm{N}_{2}\right.$, $0.2 \mathrm{~L} / \mathrm{min} \mathrm{O}_{2}$ ) the oven was heated up (heating rate $2 \mathrm{~K} / \mathrm{min}$ ) to $350{ }^{\circ} \mathrm{C}$ and the temperature was kept for $10 \mathrm{~h}$. Materials with smaller chlorine content were obtained by decreasing the amount of $\left[\mathrm{ClEt}_{3} \mathrm{Zn}_{4}(\mathrm{OiPr})_{4}\right]$ to 0.064 respectively $0.051 \mathrm{~g}$ in the precursor mixture. A $\mathrm{ZnO}$ reference was synthesized from pure $[\mathrm{EtZnOiPr}]_{4}$ precursor under the same reaction conditions.

\section{Analytical techniques}

NMR spectra were acquired on a Bruker Avance III spectrometer. X-ray diffraction was performed on a Bruker AXS D8 Advance diffractometer using $\mathrm{Cu} \mathrm{K} \alpha$ radiation. Raman measurements were conducted on a Horiba LabRAM HR spectrometer using a $532 \mathrm{~nm}$ DPSS laser and a $100 \times$ microscope objective. Room temperature PL measurements were performed on a Horiba Fluorolog spectrometer. The UV-vis measurements were done on a Varian Cary 100 scan UV-vis spectrophotometer equipped with an Ulbricht reflecting sphere. TGA analysis was performed on a Netzsch STA 449F3. EDX spectra were acquired on a Hitachi TM 3000 SEM equipped with a Bruker Quantax 70 detector. Dielectric measurements were performed with a Zahner IM6. For each sample $40 \mathrm{mg}$ of $\mathrm{ZnO}_{1-x} \mathrm{Cl}_{x}$ powder were pressed to disc-shaped pellets with a diameter of $0.8 \mathrm{~cm}$ shortly before measurement. The pellets were sandwiched between disc-shaped electrodes $(0.8 \mathrm{~cm}$ diameter) and measured under dry conditions (glove box) one after another. Micro-Raman and low-temperature photoluminescence measurements were performed using a Horiba Jobin Yvon T64000 setup with a nitrogen-cooled CCD. Low-temperature photoluminescence measurements were conducted using an Oxford micro-cryostat with a temperature range from 4 to $350 \mathrm{~K}$. The samples were excited by the $350 \mathrm{~nm}$ line of a krypton ion laser with an excitation power of no more than $500 \mu \mathrm{W}$ to avoid heating by UV absorption. Raman spectra were acquired using the $514 \mathrm{~nm}$ lines of an argon ion laser with an excitation power of $3 \mathrm{~mW}$. In both cases, an Olympus 50× microscope objective was used to focus and collect the emitted and scattered light from the sample. Time-domain $\mathrm{THz}$ spectroscopy was performed with a custom-build transmission setup employing asynchronous optical sampling (ASOPS) with two frequency-locked femtosecond Ti:sapphire lasers with repetition rates of one $\mathrm{GHz}[56,57]$. The data were partially evaluated with the commercial software TeraLyzer. The DFT calculations have been carried out using the def2-TZVP basis set for all atoms and B3LYP functional. 


\section{Results and Discussion}

\section{Precursor synthesis}

Alkylzinc-alkoxides with heterocubane structure $\left[\mathrm{CH}_{3} \mathrm{ZnOR}\right]_{4}$ are well known precursors for the synthesis of various $\mathrm{ZnO}$ materials [58-63]. It is documented that the reaction with water proceeds via the stepwise elimination of methane and the formation of hydroxo zinc species prior to polycondensation affording zinc oxide [55]. The latter process can also be interpreted as the reaction between $\mathrm{H}^{\delta+}-\mathrm{OH}$ as a Lewis and Brønsted acid and $\mathrm{CH}_{3}{ }^{{ }^{-}-}-\mathrm{Zn}$ as a Brønsted base accompanied by metathesis. Therefore, the question arises if the treatment of $\left[\mathrm{CH}_{3} \mathrm{ZnOR}\right]_{4}$ with alternative Lewis $(\mathrm{X}-\mathrm{Y})$ acids under nonaqueous conditions could lead to defined species, partially substituted at the $\mathrm{Zn}^{2+}$ position (see Scheme 1). In the current paper, we consider as potential Lewis acids either elemental halogens ( $\mathrm{X}=\mathrm{Hal}, \mathrm{Y}=\mathrm{Hal}$ ) [64] or mineral acids $(\mathrm{Y}=\mathrm{H}$, $\mathrm{X}=\mathrm{Hal})$. An advantage of this approach is that the by-product $\mathrm{CH}_{3} \mathrm{Y}(\mathrm{Y}=\mathrm{H}, \mathrm{Hal})$ is highly volatile and can be removed from equilibrium very easily.

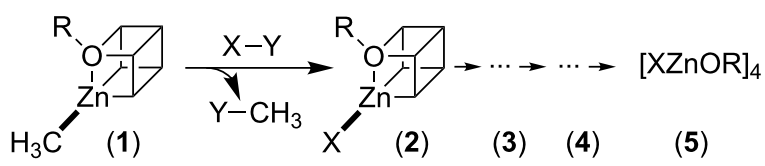
(a) $X=1$
(b) $\mathrm{X}=\mathrm{Br}$
(c) $\mathrm{X}=\mathrm{Cl}$
(d) $X=F$

Scheme 1: Synthesis of halogen-substituted alkylzinc-alkoxide precursors.

A solution of $[\mathrm{MeZnOiPr}]_{4}$ or $[\mathrm{MeZnO} t-\mathrm{Bu}]_{4}$ was reacted with $\mathrm{I}_{2}$ in toluene at $T=-78{ }^{\circ} \mathrm{C}$ (see Section Experimental). One sees an immediate decoloration of the solution, indicating the consumption of iodine. Nuclear magnetic resonance (NMR) and in particular ${ }^{1} \mathrm{H}$ NMR is well suited for the analysis of the obtained product distribution (Figure 1). Because the electronegativity of iodine $(\chi=2.66)$ is slightly higher than the group negativity of methyl $(\chi=2.31)$ [65], one sees a shift of the signals for $\mathrm{Zn}-\mathrm{CH}_{3}$ entities to lower field, the more $\mathrm{Zn}-\mathrm{I}$ units are already present in the heterocubane structure. The reaction using $[\mathrm{MeZnOiPr}]_{4}$ leads to a mixture of the starting compound 1, containing the monosubstituted product $\left[\mathrm{I}\left(\mathrm{CH}_{3}\right)_{3} \mathrm{Zn}_{4}(\mathrm{OiPr})_{4}\right]$ (2a) $(55 \%)$ and the twofold-substituted product $\left[\mathrm{I}_{2}\left(\mathrm{CH}_{3}\right)_{3} \mathrm{Zn}_{4}(\mathrm{OiPr})_{4}\right]$ (3a) (10\%) (Figure 1a). Purification via recrystallization for several times is able to remove substantial parts of the starting compound $\mathbf{1}$, but the relative amount of $\mathbf{3 a}$ remains unchanged. Obviously, iodine reacts too fast with $\mathbf{1}$, which makes double substitution possible. The possibility for the second substitution could be reduced by decreasing the overall concentration of the reactants and by selecting the less reactive tert-butyl compound $[\mathrm{MeZnO} t-\mathrm{Bu}]_{4}$. It can be seen that the monosubstituted compound $\left[\mathrm{I}\left(\mathrm{CH}_{3}\right)_{3} \mathrm{Zn}_{4}(\mathrm{O} t \text { - } \mathrm{Bu})_{4}\right]$ (2a) could now be obtained in satisfactory purity (Figure 1c). The substitution with iodine also changes the symmetry of the molecular compound $\left(\mathrm{T}_{\mathrm{d}} \rightarrow C_{3 v}\right.$ ). Whereas all tert-butoxy groups in $\mathbf{1}$ are symmetry equivalent resulting in one distinct signal in ${ }^{1} \mathrm{H}$ and ${ }^{13} \mathrm{C}$ NMR, there are now two different tert-butoxy groups with a ratio of 3:1 in 2a and slightly different chemical shifts (Figure S1, Supporting Information File 1). Further evidence of the molecular structure results from comparison and analysis of the FT-Raman spectra of $\mathbf{1}$ and 2a (see Figure S1, Supporting Information File 1). It is clearly visible that all vibration modes of the starting compound are still present in the Raman spectra 2a, which is an indication that the heterocubane framework is still intact. Additionally a sharp signal occurs at $170 \mathrm{~cm}^{-1}$, which can be assigned to the $\mathrm{Zn}-\mathrm{I}$ vibration (expected at $\left.166 \mathrm{~cm}^{-1}\right)$.

Single crystals of $\mathbf{2}$ were grown for X-ray diffraction analysis. Unfortunately, the exact structure determination was not possible due to substantial orientational disorder. The heterocubane core and the presence of iodine could be confirmed, but a satisfactory solution of the crystallographic data was not possible. Obviously, despite the lower symmetry, still all different orientations of the heterocubane in the crystal lattice were possible, leading to a randomized positioning of $\mathrm{Zn}-\mathrm{I}$ on symmetry equivalent positions. Therefore, independent analytical techniques were required for proving that the proposed molecular compound could be obtained. The most intense signal in the electron-impact mass spectrum (EIMS) of compound 2a is shown in Figure 1d. The observation of the $\left[\mathrm{I}\left(\mathrm{CH}_{3}\right)_{2} \mathrm{Zn}_{4}(\mathrm{O} t-\mathrm{Bu})_{4}\right]^{+}$fragment clearly indicates the success of our synthetic route.

A bromo-substituted compound $\left[\mathrm{Br}\left(\mathrm{CH}_{3}\right)_{3} \mathrm{Zn}_{4}(\mathrm{O} t \text { - } \mathrm{Bu})_{4}\right](\mathbf{2 b})$ could be obtained in an analogous way using $\mathrm{Br}_{2}$ as a reactant and $[\mathrm{MeZnO} t-\mathrm{Bu}]_{4}$ as starting compound (see Figure S2, Supporting Information File 1). Due to the high reactivity of elemental bromine, the reaction leads to a mixture of the starting compound, the monosubstituted product $\left[\mathrm{Br}\left(\mathrm{CH}_{3}\right)_{3} \mathrm{Zn}_{4}(\mathrm{O} t-\mathrm{Bu})_{4}\right](\mathbf{2 b})(73 \%)$ and small amounts of the twofold-substituted product $\left[\mathrm{Br}_{2}\left(\mathrm{CH}_{3}\right)_{2} \mathrm{Zn}_{4}(\mathrm{O} t \text { - } \mathrm{Bu})_{4}\right]$ (3) (6\%). However, when 1 was treated with $\mathrm{Cl}_{2}$, a complex mixture of different compounds was obtained, and purification was not possible. Therefore, alternative routes towards the desired monochlorinated compound needed to be explored. The reactivity of the starting, heterocubane compound could be reduced further, when using ethylzinc instead of the methylzinc derivative [55]. Furthermore, the dipolar character of the $\mathrm{Zn}-\mathrm{CH}_{2} \mathrm{CH}_{3}$ 

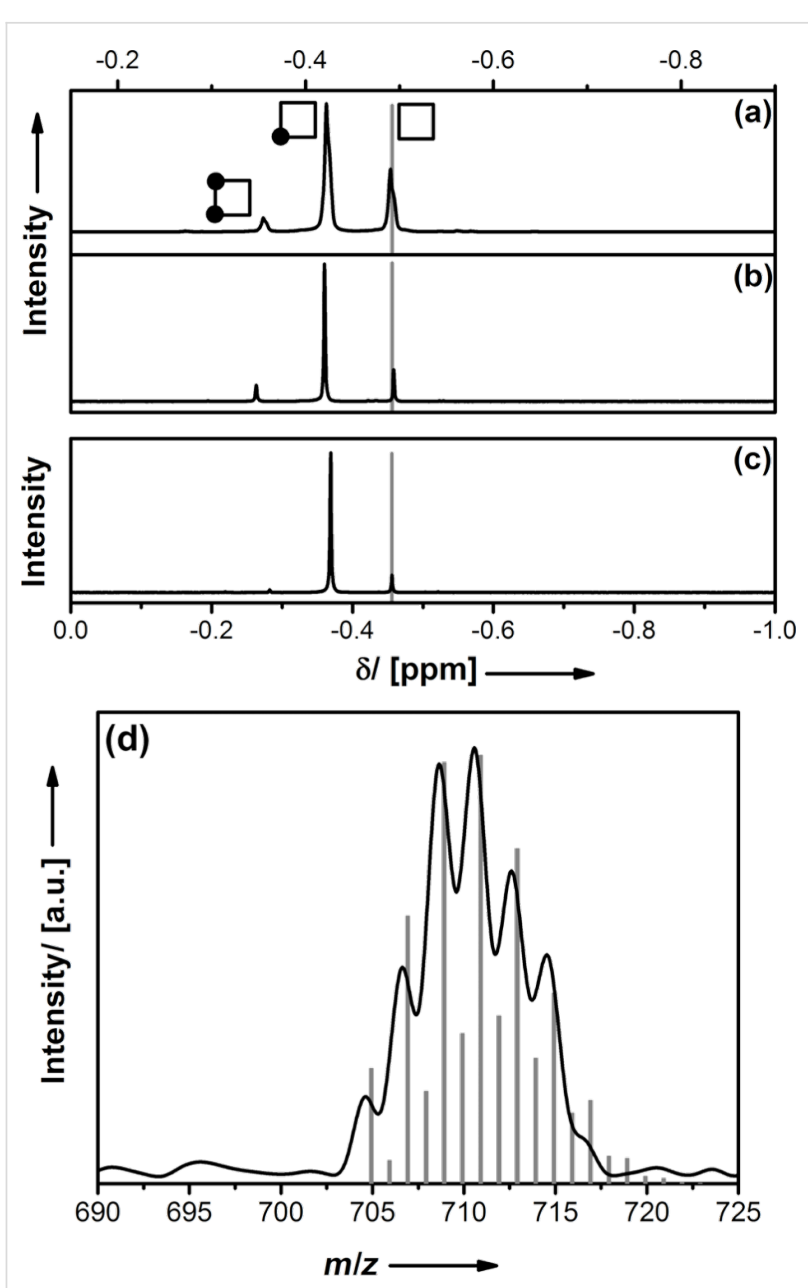

Figure 1: ${ }^{1} \mathrm{H}$ NMR spectra $\left(\mathrm{Zn}-\mathrm{CH}_{3}\right.$ region) for the reaction of $\mathrm{I}_{2}$ with $[\mathrm{MeZnOiPr}]_{4}$ before (a) and after purification (b), and for the reaction with $[\mathrm{MeZnOt}-\mathrm{Bu}]_{4}$ (c). The assignment of the signals to different $\mathrm{ZnMe} \rightarrow \mathrm{Znl}$ substitution degrees is shown schematically (a). The grey bar indicates the peak for the respective starting compound 1 . (d) Excerpt from the EI-MS spectrum (black line) of compound 2a and calculated signals for the fragment $\left[1\left(\mathrm{CH}_{3}\right)_{2} \mathrm{Zn}_{4}(\mathrm{Ot}-\mathrm{Bu})_{4}\right]^{+}$ $(m / z=710.9)$.

bond in $[\mathrm{EtZnOiPr}]_{4}$ was now addressed by using hydrogen chloride etherate $\mathrm{HCl} \cdot \mathrm{Et}_{2} \mathrm{O}$ as a reactant (see Section Experimental). NMR, FT-Raman and EIMS data showed (see Figure S3, Supporting Information File 1) that the desired compound $\left[\mathrm{Cl}(\mathrm{Et})_{3} \mathrm{Zn}_{4}(\mathrm{OiPr})_{4}\right]$ has been obtained in sufficient purity. Unfortunately, the preparation of an analogous compound containing fluorine, e.g., $\left[\mathrm{F}(\mathrm{Et})_{3} \mathrm{Zn}_{4}(\mathrm{OiPr})_{4}\right]$ as a potential single-source precursor for $\mathrm{F}$-doped $\mathrm{ZnO}$ remained an unsolved challenge for us up to this point. Conventional fluorinating agents such as $\mathrm{Me}_{3} \mathrm{SnF}, \mathrm{NEt}_{3} \cdot 3 \mathrm{HF}, \mathrm{Bu}_{4} \mathrm{~N}^{+} \mathrm{F}^{-}$or $\mathrm{Bu}_{4} \mathrm{~N}^{+} \mathrm{PF}_{6}^{-}$ either seem to be not reactive enough, or they contain irremovable water, which leads to an undesired reaction of the heterocubane precursor to $\mathrm{ZnO}$ via sol-gel chemistry [66,67]. Elemental fluorine and anhydrous HF have not been tested yet, because of security issues handling these compounds.

\section{Materials synthesis and properties}

Given the potential precursors for $\mathrm{Cl} @ \mathrm{ZnO}, \mathrm{Br} @ \mathrm{ZnO}$, and $\mathrm{I} @ \mathrm{ZnO}$, it should be noted that the difference in the ionic radius compared to $\mathrm{O}^{2-}$ is smallest for $\mathrm{Cl}^{-}$in the given series $(\Delta r=+38 \%)$. Therefore, we present the generation of chlorine containing zinc oxide first and discuss the results in detail. We chose a thermal route for the transformation of the precursors into the final materials. Thermogravimetric analysis (TGA) reveals important information about the thermal behavior of the anticipated single source precursor $\left[\mathrm{Cl}(\mathrm{Et})_{3} \mathrm{Zn}_{4}(\mathrm{OiPr})_{4}\right]$ (Figure 2a). It can be seen that there is hardly any difference between the TGA traces in inert atmosphere $\left(\mathrm{N}_{2}\right)$ and in air $\left(20 \% \mathrm{O}_{2}\right)$, which indicates that oxygen is not pivotal for the complete transformation of the precursor. The latter is an important criterion for a single-source precursor, and an advantage because oxygen can also react with halogens at higher temperature and lead to an undesired exchange. Four distinct mass loss steps can be identified from the first derivative of the TGA curve (Figure 2a). Considering the associated values for $\Delta m$, one can conclude that the first step $\left(T=131^{\circ} \mathrm{C}\right)$ is caused by the loss of the ethyl groups attached to zinc. Then, the isopropyl residue leaves the molecule as propene $\left(T=265^{\circ} \mathrm{C}\right)$. The remaining mass for $400{ }^{\circ} \mathrm{C}<T<450{ }^{\circ} \mathrm{C}$ fits very well to the residual mass expected for the complete conversion of the precursor into a non-charged product $\left(\mathrm{m} / \mathrm{m}_{0}=55.6 \%\right)$ : $2 \times(\mathbf{2 c}) \rightarrow \mathrm{ZnCl}_{2} \cdot(\mathrm{ZnO})_{7}{ }^{\prime}$.

There is an additional and final step of mass loss at $T=450{ }^{\circ} \mathrm{C}$ ( $\Delta m \approx 10 \%$ ), which fits to the amount of chlorine present in the precursor. Therefore, one can assume that chlorine is removed very rapidly from the material at temperatures above $500{ }^{\circ} \mathrm{C}$, which can also be confirmed by EDX. Obviously, it is very important to prepare the materials at lower temperatures to make sure that $\mathrm{Cl}$ remains as a dopant in the $\mathrm{ZnO}$ host. Therefore, $\mathrm{Cl} @ \mathrm{ZnO}$ was synthesized via thermal decomposition of 2c for $10 \mathrm{~h}$ at lower temperature $\left(350{ }^{\circ} \mathrm{C}\right)$ under $\mathrm{N}_{2} / \mathrm{O}_{2}$ atmosphere. The presence of $\mathrm{Cl}$ in the obtained material could be investigated by selected-area energy dispersive X-ray spectroscopy (EDX) (Figure 2b) and X-ray photoelectron spectroscopy (Figure 2c). The maximum concentration of $\mathrm{Cl}$ in the $\mathrm{ZnO}$ lattice we could reach via this method is 3.6 atom \% $\left(\equiv \mathrm{ZnO}_{0.964} \mathrm{Cl}_{0.036}\right)$. The low chlorine values compared to the molecular precursor shows that even at lower temperature, there is a slow but steady loss/evaporation of chlorine. Higher chlorine values of up to 10 atom \% could be realized for shorter periods of thermal treatment or for sacrifice of oxygen, but then the sample is contaminated with residual carbon. Because the amount of chlorine is still very high, a potential phase separation into $\mathrm{ZnO}$ and $\mathrm{ZnCl}_{2}$ could be a problem. Therefore, the material prepared at $T=350{ }^{\circ} \mathrm{C}$ was investigated using powder $\mathrm{X}$-ray diffraction (PXRD) analysis shown in Figure $3 \mathrm{a}$. 

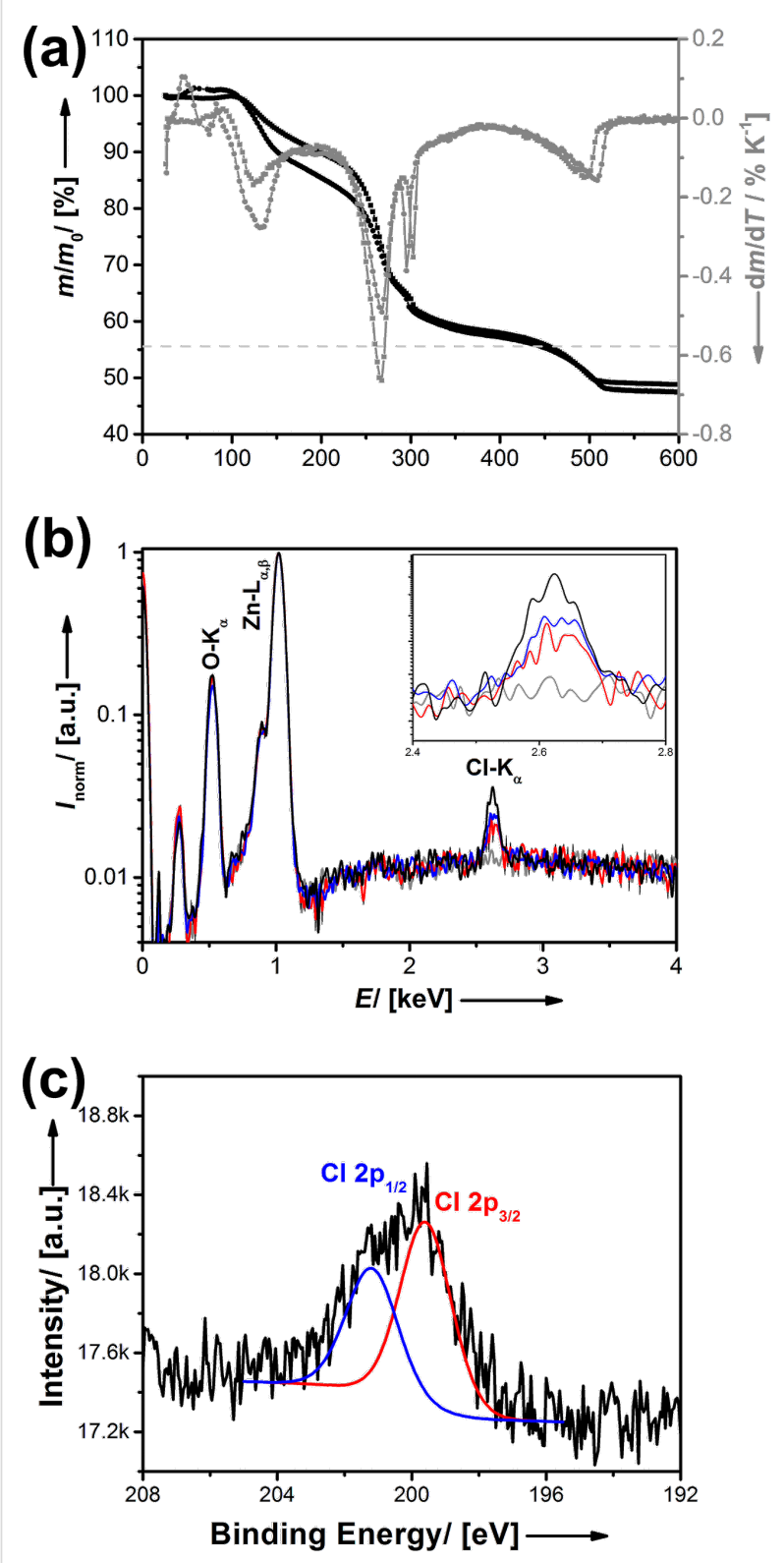

Figure 2: (a) TGA traces (black) and its first derivative (grey) of the thermal decomposition of the molecular precursor compound $\left[\mathrm{Cl}(\mathrm{Et})_{3} \mathrm{Zn}_{4}(\mathrm{OiPr})_{4}\right]$ in nitrogen atmosphere (squares) and artificial air (circles), heating rate: $5 \mathrm{~K} / \mathrm{min}$. The dashed grey line indicates the remaining mass expected for complete removal of any organic constituents. (b) EDX spectra for pure $\mathrm{ZnO}$ as a reference (grey graph) and $\mathrm{ZnO}_{1-x} \mathrm{Cl}_{x}$ materials with different chlorine content: $3.6 \%$ (black graph), $1.8 \%$ (blue graph) and $1.4 \%$ (red graph). (c) XPS spectrum for the $\mathrm{Cl}-2 \mathrm{p}$ region.

As a reference pure $\mathrm{ZnO}$ materials were prepared under analogous conditions, but using $[\mathrm{EtZnOiPr}]_{4}$ as a precursor, which yields pure, nanocrystalline $\mathrm{ZnO}$ with wurtzite structure (space group $P 6_{3} m c$, in agreement to previous studies) [49,63]. Also with $\left[\mathrm{Cl}(\mathrm{Et})_{3} \mathrm{Zn}_{4}(\mathrm{OiPr})_{4}\right]$ as a precursor there are no diffraction signals other than those for wurtzite. However, there are some subtle differences (Figure $3 b$ ). The PXRD patterns were
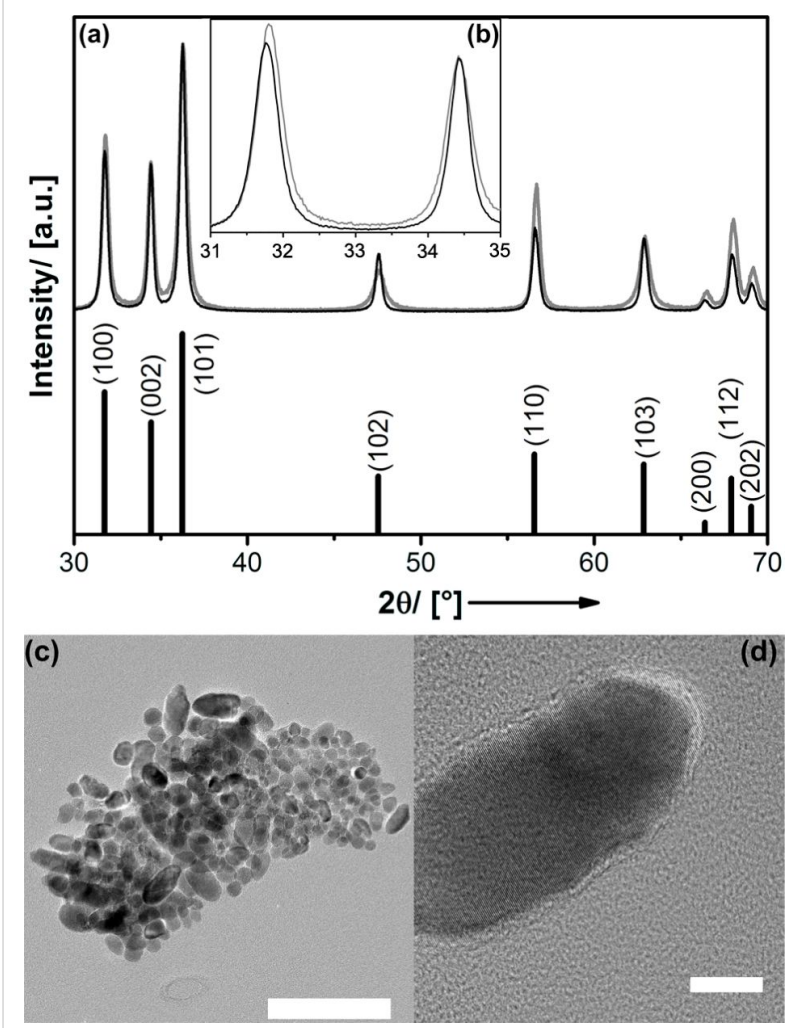

Figure 3: (a) Experimental PXRD pattern for materials prepared via thermolysis of $\left[\mathrm{Cl}(\mathrm{Et})_{3} \mathrm{Zn}_{4}(\mathrm{OiPr})_{4}\right]$ (black graph) and [EtZnOiPr $]_{4}$ (grey graph). The pattern of $\mathrm{ZnO}$ (wurtzite) is shown as black bars.

(b) Enlargement of the $2 \theta$ region $31-35^{\circ}$ for better visibility of the (100) and (002) diffraction signals. (c) TEM (scalebar $100 \mathrm{~nm}$ ) and HRTEM (scalebar $10 \mathrm{~nm}$ ) of the $\mathrm{ZnO}_{1-x} \mathrm{Cl}_{x}$ material. See also Figure S4 (Supporting Information File 1).

normalized to the intensity of the (002) signal. It can be seen that the intensity of the (100) signal of the chlorine containing material is smaller than that of the pure $\mathrm{ZnO}$ material, which suggests that the aspect ratio (extension in direction of the crystallographic $c$-axis/ $a, b$-extension) has become slightly larger due to the presence of chlorine. This can be confirmed by transmission electron microscopy (TEM) investigations shown in Figure $3 \mathrm{c}$ and Figure S4 (Supporting Information File 1).

The particle size distribution is polydisperse and almost all particles have an anisotropic, elongated shape. In contrast, the particles of the pure $\mathrm{ZnO}$ material are not elongated (see Figure S5, Supporting Information File 1). High-resolution (HR) TEM measurements show the high crystallinity of the single Cl@ZnO nanocrystals (see also Figure S4, Supporting Information File 1), the lattice plane distance seen in Figure $3 \mathrm{~d}$ is $d=0.2618 \mathrm{~nm}$. The comparison to $d_{002}=0.2604 \mathrm{~nm}$ of pure $\mathrm{ZnO}$ indicates that the main growth direction of the particles is indeed the crystallographic $c$-axis. It is interesting to note that according to the shift of the respective PXRD signals $\left(2 \theta_{100}\right.$, $2 \theta_{002}$ ) (Figure $3 b$ ) the incorporation of $\mathrm{Cl}^{-}$leads to a 
widening of the lattice in the crystallographic $a, b$-direction ( $\Delta a=\Delta b=0.146 \AA$ ) but not in $c$-direction. Thus, a potential explanation for the morphological influence of chlorine doping could be that the average density of surfaces corresponding to lattice planes with $a, b$ components will be decreased. The latter will raise the surface energy and also the apposition rate of $\mathrm{ZnO}$ species on the surfaces [68]. As a result main growth takes places perpendicular to $a, b$ (Figure $3 \mathrm{~d}$ ). The hypothesis that the presence of $\mathrm{Cl}$ also influences the growth rate could be confirmed by preparing a series of $\mathrm{ZnO}_{1-x} \mathrm{Cl}_{x}$ samples differing systematically in chlorine content. The materials were prepared from molecular precursor mixtures of $[\mathrm{EtZnOiPr}]_{4}$ and $\left[\mathrm{ClEt}_{3} \mathrm{Zn}_{4}(\mathrm{OiPr})_{4}\right]$, the required doping concentration was adjusted via the precursor composition (see Section Experimental). Nevertheless, the chlorine content determined experimentally in $\mathrm{ZnO}_{1-x} \mathrm{Cl}_{x}(x=0,0.014,0.018,0.025)$ differs slightly from that in the precursor mixture $(x=0,0.0125,0.015$, 0.02). This is because of sublimation of the $[\mathrm{EtZnOiPr}]_{4}$ precursor and weighing inaccuracies. The $\mathrm{ZnO}_{1-x} \mathrm{Cl}_{x}$ samples were analyzed by PXRD and the results are shown in Figure S6 (Supporting Information File 1). It can be seen that with higher content of chlorine (under otherwise constant conditions) also the particle size increases.

Optical spectroscopy is typically a good tool to gather first information about some electronic properties of semiconductor compounds. Absorption spectra were acquired in diffuse reflection mode $\left(R_{\text {diff }}\right)$ and are shown in Figure 4a for $\mathrm{ZnO}_{1-x} \mathrm{Cl}_{x}$ samples. It can be seen that chlorine doping leads to a shift of the band gap energy, $E_{\text {gap }}$, to higher energies, and there is a linear correlation of the blue shift with $\mathrm{Cl}$ content (see Figure S6b, Supporting Information File 1). Because in this series also the crystallite size increases with $\chi_{\mathrm{Cl}}$, it can be ruled out that the quantum size effect is responsible for the observed shift. Another explanation could be that the incorporation leads to strain.

However, this is not in agreement with PXRD data, FT-Raman data (see below) and low- $T$ photoluminescence measurements. Therefore, it seems that the enlargement of $E_{\text {gap }}$ is due to electronic reasons. For semiconductors with high doping and a significant concentration of free charge carriers one knows the so-called Burstein-Moss effect [69,70]: Valence-band electrons need to be excited into vacant states at higher energies due to a substantial population of Bloch functions near the lower edge of the conduction band. As a consequence the band gap gets overestimated. It should also be noted, that the measurements show a high transparency in the visible region $(\approx 2.7-1.7 \mathrm{eV})$. However, whether the free carrier concentration of the materials presented is here is sufficiently high, is a matter of discussion.
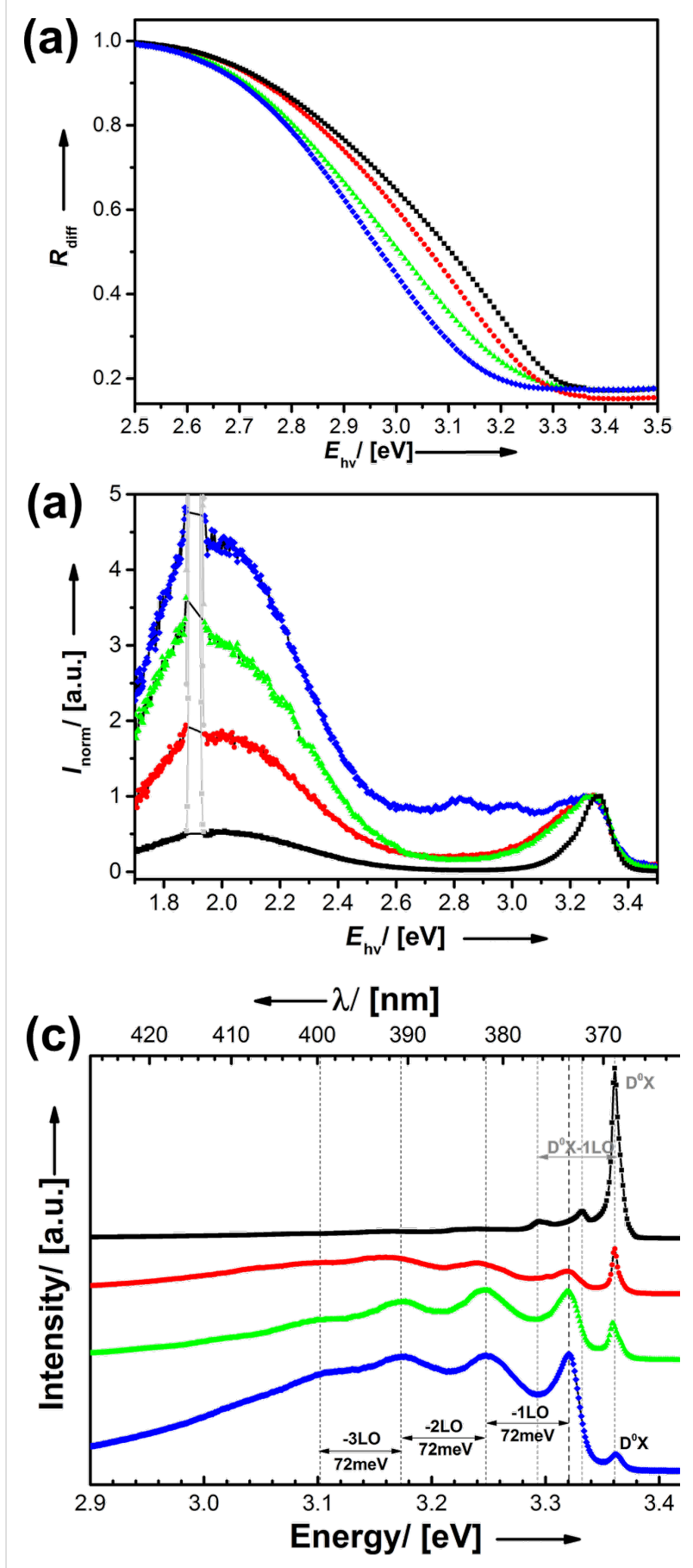

Figure 4: (a) Absorption spectra in diffuse reflection modus, room temperature photoluminescence spectra; overview (b) and band gap region (c). (d) PL spectra recorded at $T=7 \mathrm{~K}$. Hashes (blue): $\mathrm{ZnO}$ $\left(D_{\text {cryst }}=22 \mathrm{~nm}\right)$; triangles (green): $\mathrm{ZnO}_{0.986} \mathrm{Cl}_{0.014}\left(D_{\text {cryst }}=25 \mathrm{~nm}\right)$; circles (red): $\mathrm{ZnO}_{0.982} \mathrm{Cl}_{0.018}\left(D_{\text {cryst }}=27 \mathrm{~nm}\right.$ ); squares (black): $\mathrm{ZnO}_{0.964} \mathrm{Cl}_{0.036}\left(D_{\text {cryst }}=37 \mathrm{~nm}\right)$.

The described blue shift can be confirmed by photoluminescence (PL) spectroscopy recorded at room temperature (Figure 4c). Furthermore, $\mathrm{Cl}$ doping strongly affects the 
so-called green luminescence, which is associated with electrons trapped at oxygen vacancies $\left(\mathrm{V}_{\mathrm{O}} \bullet\right.$ in Kröger-Vink notation) present in many different types of $\mathrm{ZnO}$ materials [63]. It can be seen that the intensity of the green luminescence (normalized to the near band-edge emission) gradually decreases with increasing amount of chlorine (Figure 4b). The latter observation might be explained as follows. Substitution of $\mathrm{O}^{2-}$ by $\mathrm{Cl}^{-}$leads to an excess of positive charges in the lattice $\left(\mathrm{Cl}_{\mathrm{O}} \bullet\right.$ ). Thus, point defects that also lead to relative positive charges such as $\mathrm{V}_{\mathrm{O}} \bullet$ become more and more unfavorable and the green luminescence is suppressed. The low-temperature photoluminescence spectra measured at $7 \mathrm{~K}$ (Figure $4 \mathrm{~d}$ ) provide detailed information about the near band-edge luminescence. The spectrum of the undoped $\mathrm{ZnO}$ sample is dominated by a transition at $3.32 \mathrm{eV}$. This zero-phonon line is repeated by longitudinal optical phonon replicas with an energy spacing of $72 \mathrm{meV}$. The high intensity of the phonon replicas is characteristic for a strong electron-phonon coupling as it is typically observed for donor acceptor pairs (DAP) [71], although the energy is closer to the $3.31 \mathrm{eV}$ free-to-bound transition reported by Schirra et al. [72]. With increasing $\mathrm{Cl}$ concentration the signal disappears. At the same time a transition, which can be assigned to bound exciton $\left(\mathrm{D}^{0} \mathrm{X}\right)$, becomes more intensive. The spectral position coincides with typical shallow donor bound excitons in the neutral charge state and is found very close to the well-known position of the shallow $\mathrm{Ga}$ donor $\mathrm{D}^{0} \mathrm{X} \mathrm{I}_{8}$ or $\mathrm{Al}$ $\mathrm{D}^{0} \mathrm{X} \mathrm{I}_{6}$ [73]. In addition an emission line at $3.333 \mathrm{eV}$ is visible in the spectra of $\mathrm{ZnO}_{1-x} \mathrm{Cl}_{x}$ with $x=2.5 \%$. This transition, which is labeled $\mathrm{Y}_{0}$, is assigned to a donor-bound exciton recombination at a structural defect [74]. The spectra of the $2.5 \%$ sample are dominated by the $\mathrm{D}^{0} \mathrm{X}$ shallow donor-bound exciton recombination with one phonon replica of the $\mathrm{D}^{0} \mathrm{X}$ visible. The low-temperature PL spectrum of the highest doped $\mathrm{Cl} @ \mathrm{ZnO}$ sample resembles those of good quality $\mathrm{ZnO}$ single crystals. Once again the PL measurements demonstrate that the crystal quality of $\mathrm{ZnO}$ materials prepared from molecular precursors can be improved by controlled $\mathrm{Cl}$ doping. The synthetic strategy via molecular precursors enables not only a high doping concentration, but also the access to $\mathrm{ZnO}$ with a low defect density.

Further information can be acquired by vibrational spectroscopy. Raman spectroscopy is a powerful method to investigate structural and electronic properties of semiconductors [75]. The non-polar $\mathrm{E}_{2}{ }^{\text {high }}$ mode of hexagonal wurtzite $\mathrm{ZnO}$ is very sensitive to lattice strain [76]. The LO mode can interact with electrons from the conduction band, the magnitude depends on the free carrier distribution [77,78]. The Raman spectra shown in Figure 5 are dominated by the characteristic vibrational modes $\mathrm{E}_{2}{ }^{\text {low }}$ at about $98 \mathrm{~cm}^{-1}$ and $\mathrm{E}_{2}{ }^{\text {high }}$ at about $439 \mathrm{~cm}^{-1}$ [79].
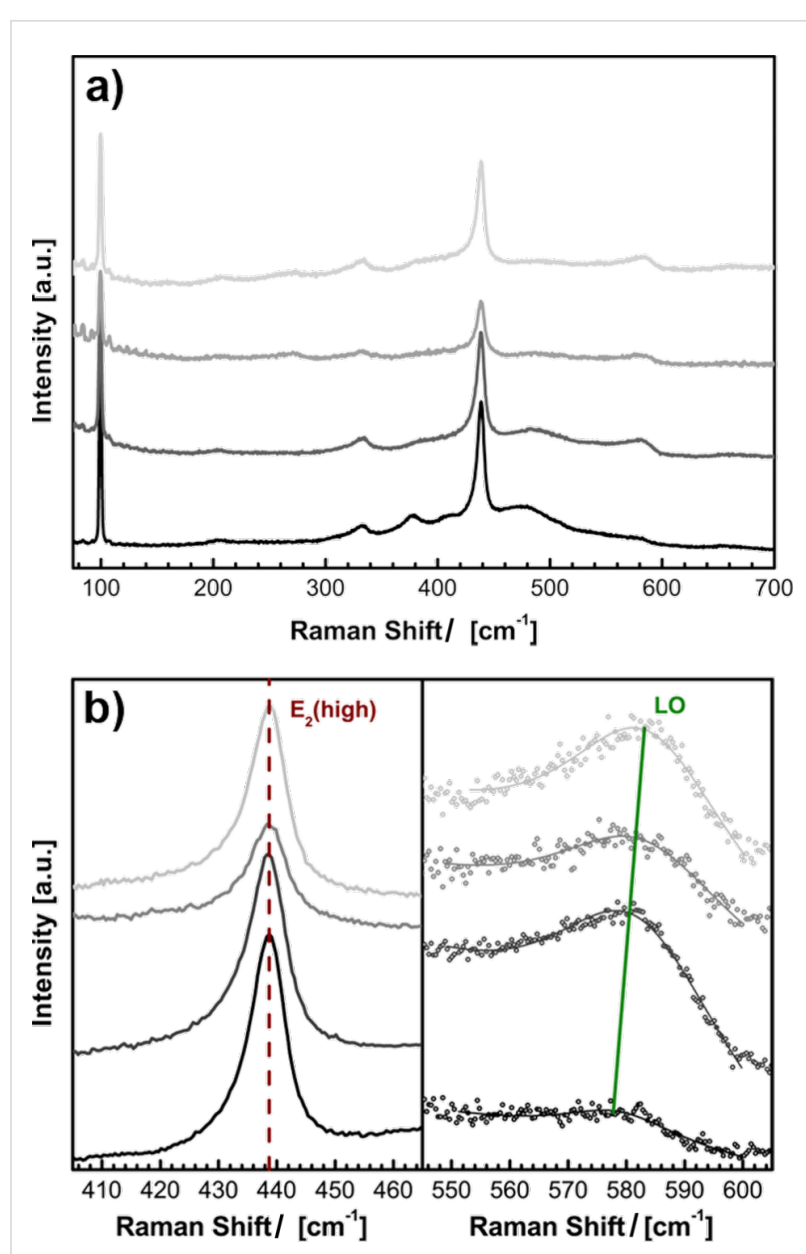

Figure 5: (a) Raman spectra of $\mathrm{ZnO}_{1-x} \mathrm{Cl}_{x}: x=0.0 \%$ (black), $1.4 \%$ (dark grey), $1.8 \%$ (grey) and $2.5 \%$ (light grey); (b) Raman spectra in the range of the non-polar $E_{2}$ (high) and polar LO modes.

The spectral position of the $\mathrm{E}_{2}{ }^{\text {high }}$ mode remains constant with increased doping concentration, which proves that the $\mathrm{Cl}$ doping does not affect strain in the $\mathrm{ZnO}$ lattice (Figure $5 \mathrm{~b}$ ). The spectral position of the LO mode is shifted to higher wavelengths with increased $\mathrm{Cl}$ doping. This effect is based on longitudinal optical phonon-plasmon coupling and describes the interaction of collective oscillating free carriers (plasmons) with LO phonons [80].

Consequently, the concentration of free carriers increases with $\mathrm{Cl}$ doping. The dielectric properties of thin $\mathrm{ZnO}_{1-x} \mathrm{Cl}_{x}$ pellets were investigated with impedance spectroscopy. In the Nyquist plot in Figure 6 the imaginary part of the impedance is plotted as a function of the real part. For materials having resistive and capacitive components a series of two semicircles usually occurs in the Nyquist plot. The semicircle in the high frequency region is assigned to grain contribution while the semicircle in the low frequency region is assigned to grain boundary contribution [81]. Because only one single semicircle at low frequen- 
cies is present in Figure 6, it can be concluded that grainboundary resistance dominates over grain resistance. The resistance values of the $\mathrm{Cl} @ \mathrm{ZnO}$ pellets are obtained from the circular arc intercepts on the $Z^{\prime}$-axis. For $x=1.4 \%$ the resistance is reduced by one half compared to undoped $\mathrm{ZnO}$, which shows that the conductivity decreases due to $\mathrm{Cl}$ doping. However, one has to be very careful for avoiding an overinterpretation of impedance data, because the grain-boundary influence can significantly differ from sample to sample. This can also be seen in Figure S6b (Supporting Information File 1). For higher $\mathrm{Cl}$ content, when the tendency for the formation of separated particles is more pronounced (Figure 3), the resistivity raises due to the enhanced portion of grain boundaries.

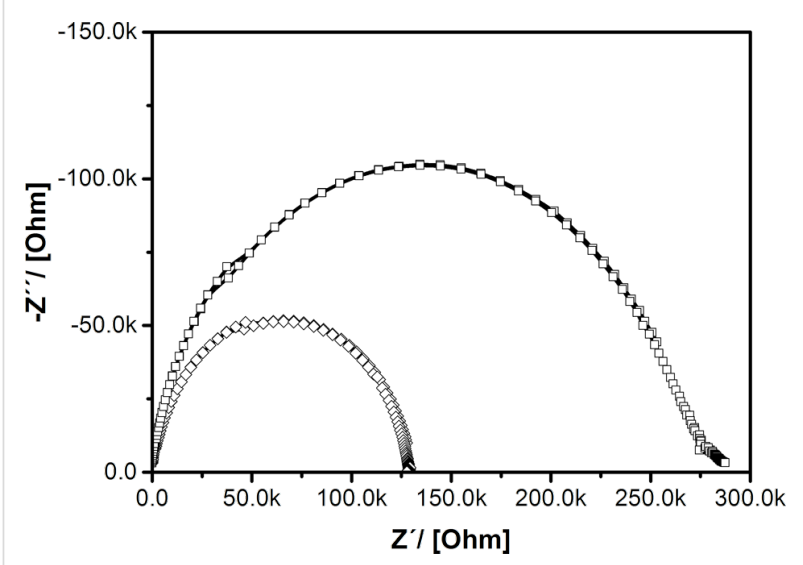

Figure 6: Impedance spectra (Nyquist Plots) of $\mathrm{ZnO}_{0.986} \mathrm{Cl}_{0.014}$ (hashes) and pure $\mathrm{ZnO}$ (squares) prepared in an analogous way.

To get further information about the influence of doping on the conductivity, measurements of the complex dielectric function in the $\mathrm{THz}$ frequency range were performed. Time-domain $\mathrm{THz}$ spectroscopy $[56,57]$ is a method to investigate the transmission and/or reflection of a sample in the $\mathrm{THz}$ frequency range. The transmitted electric field is directly sampled in the time domain, which provides amplitude and phase information of the transmission spectrum. A comparison with a reference measurement allows for the calculation of the complex dielectric function $\varepsilon(w)$ of the sample material $[82,83]$. Free-carrier absorption at low carrier concentrations and IR-active lattice vibrations determine the complex response function in the $\mathrm{THz}$ frequency range [84]. A theoretical approach for modelling the complex dielectric response is the Drude model, see Figure 7a.

The Drude model only takes into account free carriers and describes the meta-like background absorption of free carriers in the material. The actual shape of the Drude function strongly depends on the square of the plasma frequency, which is proportional to the number $N$ of free carriers. Additional
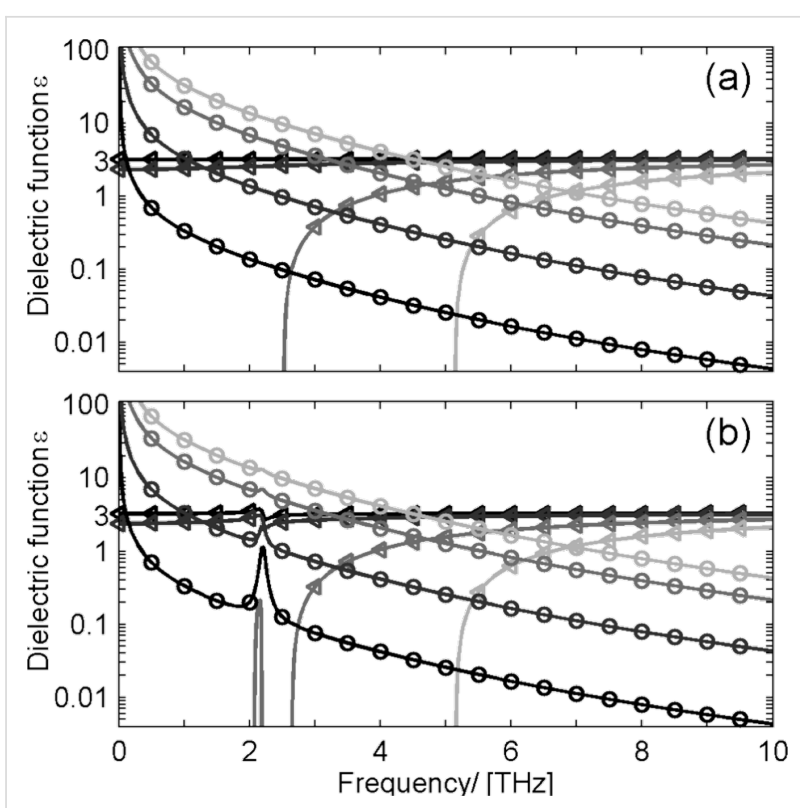

Figure 7: Theoretical model for dielectric function $\varepsilon(w)$ for different carrier concentrations $N=1 \times 10^{14}$ (black lines), $N=1 \times 10^{15}$ (dark gray lines), $N=5 \times 10^{15}$ (gray lines), and $N=1 \times 10^{16}$ (light gray lines). The triangles mark the real parts $\varepsilon_{1}$ and the circles the imaginary parts $\varepsilon_{2}$; (a) Drude model; (b) Drude-Lorentz model with a resonance at $2 \mathrm{THz}$.

phonon oscillation are introduced as Lorentz oscillators (see Figure 7b). For nanostructured materials the Drude model has to be modified [84,85]. However, for a first step of interpretation of the experimental data the most salient changes with carrier densities are already visible in the Drude model. Figure 8 shows the real and imaginary part of $\varepsilon$ for the measured $\mathrm{ZnO}_{1-x} \mathrm{Cl}_{x}$ pellets obtained from time-domain $\mathrm{THz}$ spectroscopy. Two features are most prominent. First there is a phonon resonance at about $2 \mathrm{THz}$ which is strongly depending in intensity on the $\mathrm{Cl}$ concentration. It is not yet clear which lattice mode gives rise to this IR-active mode. Low-frequency Raman measurements have shown that there is no Raman-active mode at a corresponding Raman shift of about $67 \mathrm{~cm}^{-1}$ observable. Second the value of $\varepsilon_{1}$ is nearly the same for all $\mathrm{ZnO}_{1-x} \mathrm{Cl}_{x}$. Compared to Figure $7 \mathrm{a}$ we conclude that the detected change in the number of free carriers is smaller than in the theoretical model. However, it should be noted, that any change in the Drude response of the free carriers in this frequency range is strongly masked by the contribution of the $\mathrm{Cl}$-induced phonon mode.

\section{Bromine- and iodine-containing $\mathrm{ZnO}$ materials}

Using the precursors $\mathbf{2 a}, \mathbf{b}$ containing iodine and bromine analogous experiments were performed. Taking the example of $\left[\mathrm{IMe}_{3} \mathrm{Zn}_{4}(\mathrm{O} t-\mathrm{Bu})_{4}\right]$ (2a), the influence of the decomposition temperature on the composition of $\mathrm{ZnO}_{1-x} \mathrm{I}_{x}$ materials is demonstrated. The iodine content decreases strongly with 

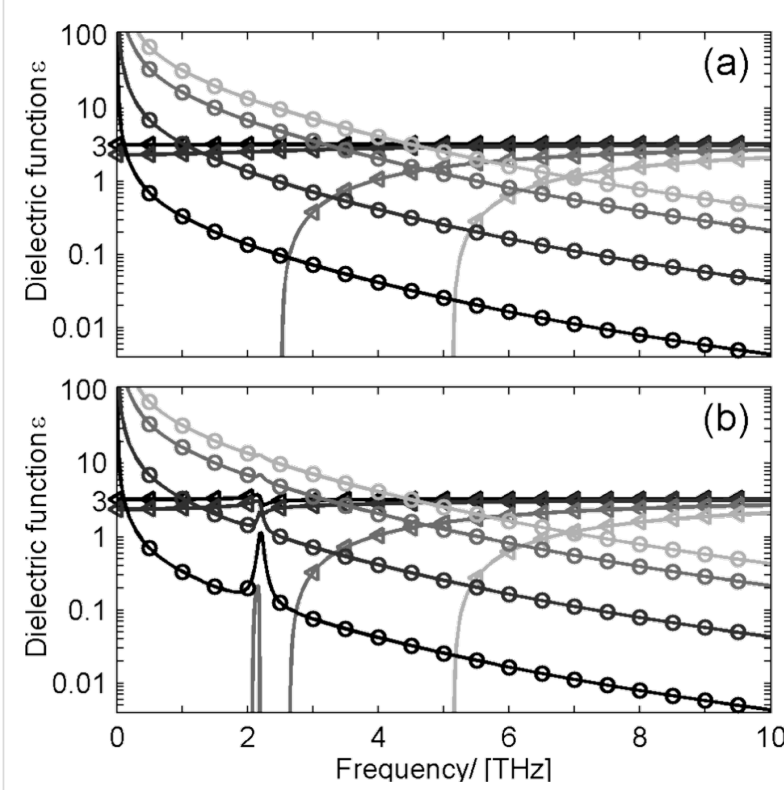

Figure 8: Measured dielectric function of $\mathrm{ZnO}_{1-x} \mathrm{Cl}_{x}$ (a) real part; (b) imaginary part with $x=0.0 \%$ (black lines), $1.4 \%$ (dark gray lines), $1.8 \%$ (gray lines) and $2.5 \%$ (light gray lines); An infrared-active phonon at about about $2 \mathrm{THz}$ is scaling in intensity with increasing $\mathrm{Cl}$ concentration.

increasing decomposition temperature (Figure S7, Supporting Information File 1). $\mathrm{ZnO}_{1-x} \mathrm{I}_{x}$ prepared at $200{ }^{\circ} \mathrm{C}$ exhibits an iodine content of $8.8 \%$, the sample prepared at $350{ }^{\circ} \mathrm{C}$ only of $0.5 \%$. Probably the precursor reacts with volatile compounds such as iodine alkyls or elemental iodine. $\mathrm{ZnO}_{1-x} \mathrm{Br}_{x}$ can be prepared analogously via thermal decomposition of $\left[\mathrm{BrMe}_{3} \mathrm{Zn}_{4}(\mathrm{O} t-\mathrm{Bu})_{4}\right]$ (2b) (Figure S8, Supporting Information File 1).

\section{Conclusion}

Starting from well-known $\mathrm{ZnO}$ precursors with ' $\mathrm{Zn}_{4} \mathrm{O}_{4}$ ' heterocubane framework, we showed that it is possible to introduce one single Hal- $\mathrm{Zn}$ entity $(\mathrm{Hal}=\mathrm{I}, \mathrm{Br}, \mathrm{Cl})$. These compounds have been proven to be novel single-source precursors for halogen-doped $\mathrm{ZnO}$ materials. The stability of the Hal@ZnO materials against thermal loss of Hal depends on the difference in ionic radius of $\mathrm{O}^{2-}$ compared to $\mathrm{Hal}^{-} . \mathrm{Cl} @ \mathrm{ZnO}$ materials are stable at temperatures below $500{ }^{\circ} \mathrm{C}$, and nanocrystalline powders differing in $\mathrm{Cl}$ content could be prepared. It was seen that the presence of $\mathrm{Cl}$ leads to a widening of the $\mathrm{ZnO}$ lattice in $a, b$-direction, and as a consequence anisotropic nanoparticles with preferential growth in $c$-direction were obtained. The latter result represents an interesting perspective to understand and to control anisotropic particle growth.

However, the main focus of the current study was to prove the successful incorporation of $\mathrm{Cl}$, and in particular its positioning on the lattice positions of oxygen $\left(\mathrm{Cl}_{\mathrm{O}} \bullet\right.$, which leads to $\mathrm{n}$-doping and opens up a perspective to use the materials as potential TCO materials in the future. Although it could be proven by several methods, that the desired materials were obtained, due to the current, powder-like nature, the electronic properties are yet dominated by grain boundary effects. Therefore, future research in this field will address the synthesis of thin films minimizing the amount of grain boundaries. Furthermore, we could not yet realize a F-containing precursor. F@ZnO materials are also expected to be interesting TCO candidates and potential ITO substitutes.

\section{Supporting Information}

\section{Supporting Information File 1}

Additional experimental data.

[http://www.beilstein-journals.org/bjnano/content/

supplementary/2190-4286-6-222-S1.pdf]

\section{Acknowledgements}

The Carl-Zeiss foundation is acknowledged for funding (project REFINE). M.R.W. acknowledges support from the postdoctoral Marie Curie Fellowship (IEF) HeatProNano (Grant No. 628197). The work of J.F and T.D. was supported through the Deutsche Forschungsgemeinschaft (DFG) through the SFB 767. ICN2 acknowledges support from the Spanish MICINN projects TAPHOR (Grant MAT2012-31392) and nanoTHERM (Grant No. CSD2010-0044).

\section{References}

1. Ginley, D. S.; Bright, C. MRS Bull. 2000, 25, 15. doi: $10.1557 / \mathrm{mrs} 2000.256$

2. Gust, D.; Moore, T. A.; Moore, A. L. Acc. Chem. Res. 2009, 42, 1890. doi:10.1021/ar900209b

3. Habas, S. E.; Platt, H. A. S.; van Hest, M. F. A. M.; Ginley, D. S. Chem. Rev. 2010, 110, 6571. doi:10.1021/cr100191d

4. Liu, H. Y.; Avrutin, V.; Izyumskaya, N.; Özgür, Ü.; Morkoc, H. Superlattices Microstruct. 2010, 48, 458. doi:10.1016/j.spmi.2010.08.011

5. Hecht, D. S.; Hu, L.; Irvin, G. Adv. Mater. 2011, 23, 1482. doi:10.1002/adma.201003188

6. Kim, K. S.; Zhao, Y.; Jang, H.; Lee, S. Y.; Kim, J. M.; Kim, K. S.; Ahn, J.-H.; Kim, P.; Choi, J.-Y.; Hong, B. H. Nature 2009, 457, 706. doi:10.1038/nature07719

7. Bae, S.; Kim, H.; Lee, Y.; Xu, X.; Park, J.-S.; Zheng, Y.; Balakrishnan, J.; Lei, T.; Kim, H. R.; Song, Y. I.; Kim, Y.-J.; Kim, K. S.; Özyilmaz, B.; Ahn, J. H.; Hong, B. H.; lijima, S. Nat. Nanotechnol. 2010, 5, 574. doi:10.1038/nnano.2010.132

8. Wu, Z.; Chen, Z.; Du, X.; Logan, J. M.; Sippel, J.; Nikolou, M.; Kamaras, K.; Reynolds, J. R.; Tanner, D. B.; Hebard, A. F.; Rinzler, A. G. Science 2004, 305, 1273. doi:10.1126/science.1101243 
9. De, S.; Higgins, T. M.; Lyons, P. E.; Doherty, E. M.; Nirmalraj, P. N.; Blau, W. J.; Boland, J. J.; Coleman, J. N. ACS Nano 2009, 3, 1767. doi:10.1021/nn900348c

10. Perelaer, J.; de Gans, B.-J.; Schubert, U. S. Adv. Mater. 2006, 18, 2101. doi:10.1002/adma.200502422

11. Forrest, S. R. Nature 2004, 428, 911. doi:10.1038/nature02498

12. Minami, T. Semicond. Sci. Technol. 2005, 20, S35. doi:10.1088/0268-1242/20/4/004

13. Fortunato, E.; Ginley, D.; Hosono, H.; Paine, D. C. MRS Bull. 2007, 32, 242. doi:10.1557/mrs2007.29

14. Lewis, B. G.; Paine, D. C. MRS Bull. 2000, 25, 22. doi:10.1557/mrs2000.147

15. Minami, T. Thin Solid Films 2008, 516, 1314. doi:10.1016/j.tsf.2007.03.082

16. Minami, T. Thin Solid Films 2008, 516, 5822. doi:10.1016/j.tsf.2007.10.063

17. Klingshirn, C. Phys. Status Solidi B 2007, 244, 3027. doi:10.1002/pssb.200743072

18. Klingshirn, C. ChemPhysChem 2007, 8, 782. doi:10.1002/cphc.200700002

19. Maksimov, O. Rev. Adv. Mater. Sci. 2010, 24, 26.

20. Liu, L.; Xu, J.; Wang, D.; Jiang, M.; Wang, S.; Li, B.; Zhang, Z.; Zhao, D.; Shan, C.-X.; Yao, B.; Shen, D. Z. Phys. Rev. Lett. 2012, 108, 215501. doi:10.1103/PhysRevLett.108.215501

21. Yoo, J.; Lee, J.; Kim, S.; Yoon, K.; Park, I. J.; Dhungel, S. K.; Karunagaran, B.; Mangalaraj, D.; Yi, J. Thin Solid Films 2005, 480-481, 213. doi:10.1016/j.tsf.2004.11.010

22. Agura, H.; Suzuki, A.; Matsushita, T.; Aoki, T.; Okuda, M. Thin Solid Films 2003, 445, 263. doi:10.1016/S0040-6090(03)01158-1

23. Yakuphanoglu, F.; Caglar, Y.; Ilican, S.; Caglar, M. Physica B 2007, 394, 86. doi:10.1016/j.physb.2007.02.014

24. Yoon, H. S.; Lee, K. S.; Lee, T. S.; Cheong, B.; Choi, D. K.; Kim, D. H.; Kim, W. M. Sol. Energy Mater. Sol. Cells 2008, 92, 1366. doi:10.1016/j.solmat.2008.05.010

25. Sanchez-Juarez, A.; Tiburcio-Silver, A.; Ortiz, A Sol. Energy Mater. Sol. Cells 1998, 52, 301. doi:10.1016/S0927-0248(97)00246-8

26. Cui, J. B.; Soo, Y. C.; Chen, T. P.; Gibson, U. J. J. Phys. Chem. C 2008, 112, 4475. doi:10.1021/jp710855z

27. Fan, J.; Shavel, A.; Zamani, R.; Fábrega, C.; Rousset, J.; Haller, S.; Güell, F.; Carrete, A.; Andreu, T.; Arbiol, J.; Morante, J. R.; Cabot, A. Acta Mater. 2011, 59, 6790. doi:10.1016/j.actamat.2011.07.037

28. Lupan, O.; Pauporté, T.; Chow, L.; Viana, B.; Pellé, F.; Ono, L. K.; Cuenya, B. R.; Heinrich, H. Appl. Surf. Sci. 2010, 256, 1895. doi:10.1016/j.apsusc.2009.10.032

29. Rousset, J.; Saucedo, E.; Herz, K.; Lincot, D. Prog. Photovoltaics 2011, 19, 537. doi:10.1002/pip.1061

30. Rousset, J.; Saucedo, E.; Lincot, D. Chem. Mater. 2009, 21, 534. doi:10.1021/cm802765c

31. Lu, J. G.; Fujita, S.; Kawaharamura, T.; Nishinaka, H.; Kamada, Y.; Ohshima, T.; Ye, Z. Z.; Zeng, Y. J.; Zhang, Y. Z.; Zhu, L. P.; He, H. P.; Zhao, B. H. J. Appl. Phys. 2007, 101, 083705. doi:10.1063/1.2721374

32. Lu, J. G.; Ye, Z. Z.; Zeng, Y. J.; Zhu, L. P.; Wang, L.; Yuan, J.; Zhao, B. H.; Liang, Q. L. J. Appl. Phys. 2006, 100, 073714. doi:10.1063/1.2357638

33. Yousefi, R.; Jamah-Sheini, F. Ceram. Int. 2012, 38, 5821. doi:10.1016/j.ceramint.2012.04.030

34. Lee, J.-c.; Subramaniam, N. G.; Lee, J.-w.; Lee, J.-c.; Kang, T.-w. Phys. Status Solidi A 2013, 210, 2638. doi:10.1002/pssa.201330042
35. Burda, C.; Chen, X.; Narayanan, R.; El-Sayed, M. A. Chem. Rev. 2005, 105, 1025. doi:10.1021/cr030063a

36. Yin, Y.; Alivisatos, A. P. Nature 2005, 437, 664. doi:10.1038/nature04165

37. Mohanan, J. L.; Arachchige, I. U.; Brock, S. L. Science 2005, 307, 397. doi:10.1126/science.1104226

38. Livage, J.; Henry, M.; Sanchez, C. Prog. Solid State Chem. 1988, 18, 259. doi:10.1016/0079-6786(88)90005-2

39. Niederberger, M. Acc. Chem. Res. 2007, 40, 793. doi:10.1021/ar600035e

40. Norris, D. J.; Efros, A. L.; Erwin, S. C. Science 2008, 319, 1776. doi:10.1126/science.1143802

41. Barrelet, C. J.; Wu, Y.; Bell, D. C.; Lieber, C. M. J. Am. Chem. Soc. 2003, 125, 11498. doi:10.1021/ja036990g

42. Cumberland, S. L.; Hanif, K. M.; Javier, A.; Khitrov, G. A.; Strouse, G. F.; Woessner, S. M.; Yun, C. S. Chem. Mater. 2002, 14, 1576. doi:10.1021/cm010709k

43. Polarz, S.; Roy, A.; Merz, M.; Halm, S.; Schröder, D.; Schneider, L.; Bacher, G.; Kruis, F. E.; Driess, M. Small 2005, 1, 540. doi:10.1002/smll.200400085

44. Veith, M.; Mathur, S.; Lecerf, N.; Huch, V.; Decker, T.; Beck, H. P.; Eiser, W.; Haberkorn, R. J. Sol-Gel Sci. Technol. 2000, 17, 145. doi:10.1023/A:1008795419020

45. Singh, S.; Chaturvedi, J.; Bhattacharya, S. RSC Adv. 2014, 4, 11469 doi:10.1039/c3ra48025a

46. Aksu, Y.; Frasca, S.; Wollenberger, U.; Driess, M.; Thomas, A. Chem. Mater. 2011, 23, 1798. doi:10.1021/cm103087p

47. Polarz, S.; Pueyo, C. L.; Krumm, M. Inorg. Chim. Acta 2010, 363, 4148. doi:10.1016/j.ica.2010.06.053

48. Polarz, S.; Roy, A.; Lehmann, M.; Driess, M.; Kruis, F. E.; Hoffmann, A.; Zimmer, P. Adv. Funct. Mater. 2007, 17, 1385. doi:10.1002/adfm.200700139

49. Polarz, S.; Strunk, J.; Ischenko, V.; van den Berg, M. W. E.; Hinrichsen, O.; Muhler, M.; Driess, M. Angew. Chem., Int. Ed. 2006, 45, 2965. doi:10.1002/anie.200503068

50. Polarz, S.; Orlov, A. V.; van den Berg, M. W. E.; Driess, M. Angew. Chem., Int. Ed. 2005, 44, 7892. doi:10.1002/anie.200501212

51. Orlov, A.; Roy, A.; Lehmann, M.; Driess, M.; Polarz, S. J. Am. Chem. Soc. 2007, 129, 371. doi:10.1021/ja0659626

52. Dreher, M. A.; Krumm, M.; Lizandara-Pueyo, C.; Polarz, S. Dalton Trans. 2010, 39, 2232. doi:10.1039/b916253b

53. Polarz, S.; Orlov, A.; Hoffmann, A.; Wagner, M. R.; Rauch, C.; Kirste, R.; Gehlhoff, W.; Aksu, Y.; Driess, M.; van den Berg, M. W. E.; Lehmann, M. Chem. Mater. 2009, 21, 3889. doi:10.1021/cm9014223

54. Lehr, D.; Luka, M.; Wagner, M. R.; Bügler, M.; Hoffmann, A.; Polarz, S. Chem. Mater. 2012, 24, 1771. doi:10.1021/cm300239q

55. Lizandara-Pueyo, C.; van den Berg, M. W. E.; De Toni, A.; Goes, T.; Polarz, S. J. Am. Chem. Soc. 2008, 130, 16601. doi:10.1021/ja804071h

56. Gebs, R.; Klatt, G.; Janke, C.; Dekorsy, T.; Bartels, A. Opt. Express 2010, 18, 5974. doi:10.1364/OE.18.005974

57. Klatt, G.; Gebs, R.; Schäfer, H.; Nagel, M.; Janke, C.; Bartels, A.; Dekorsy, T. IEEE J. Sel. Top. Quantum Electron. 2011, 17, 159. doi:10.1109/JSTQE.2010.2047635

58. Pueyo, C. L.; Siroky, S.; Landsmann, S.; van den Berg, M. W. E.; Wagner, M. R.; Reparaz, J. S.; Hoffmann, A.; Polarz, S. Chem. Mater. 2010, 22, 4263. doi:10.1021/cm101240n

59. Dilger, S.; Lizandara-Pueyo, C.; Krumm, M.; Polarz, S. Adv. Mater. 2012, 24, 543. doi:10.1002/adma.201103557 
60. Lizandara-Pueyo, C.; Siroky, S.; Wagner, M. R.; Hoffmann, A.; Reparaz, J. S.; Lehmann, M.; Polarz, S. Adv. Funct. Mater. 2011, 21, 295. doi:10.1002/adfm.201000997

61. Polarz, S.; Orlov, A. V.; Schüth, F.; Lu, A. H. Chem. - Eur. J. 2007, 13, 592. doi:10.1002/chem.200600428

62. Polarz, S.; Neues, F.; van den Berg, M. W. E.; Grünert, W.; Khodeir, L. J. Am. Chem. Soc. 2005, 127, 12028. doi:10.1021/ja0516514

63. Ischenko, V.; Polarz, S.; Grote, D.; Stavarache, V.; Fink, K.; Driess, M. Adv. Funct. Mater. 2005, 15, 1945. doi:10.1002/adfm.200500087

64. Driess, M.; Merz, K.; Rell, S. Eur. J. Inorg. Chem. 2000, 2517. doi:10.1002/1099-0682(200012)2000:12<2517::AID-EJIC2517>3.0.CO ;2-V

65. Bratsch, S. G. J. Chem. Educ. 1985, 62, 101. doi:10.1021/ed062p101

66. Krumm, M.; Pueyo, C. L.; Polarz, S. Chem. Mater. 2010, 22, 5129. doi:10.1021/cm1006907

67. Lizandara-Pueyo, C.; Morant-Miñana, M. C.; Wessig, M.; Krumm, M.; Mecking, S.; Polarz, S. RSC Adv. 2012, 2, 5298. doi:10.1039/c2ra20343j

68. Polarz, S. Adv. Funct. Mater. 2011, 21, 3214. doi:10.1002/adfm.201101205

69. Burstein, E. Phys. Rev. 1954, 93, 632. doi:10.1103/PhysRev.93.632

70. Moss, T. S. Proc. Phys. Soc., London, Sect. B 1954, 67, 775. doi:10.1088/0370-1301/67/10/306

71. Lautenschlaeger, S.; Eisermann, S.; Haas, G.; Zolnowski, E. A.; Hofmann, M. N.; Laufer, A.; Pinnisch, M.; Meyer, B. K.; Wagner, M. R.; Reparaz, J. S.; Callsen, G.; Hoffmann, A.; Chernikov, A.; Chatterjee, S.; Bornwasser, V.; Koch, M. Phys. Rev. B 2012, 85 , 235204. doi:10.1103/PhysRevB.85.235204

72. Schirra, M.; Schneider, R.; Reiser, A.; Prinz, G. M.; Feneberg, M.; Biskupek, J.; Kaiser, U.; Krill, C. E.; Thonke, K.; Sauer, R. Phys. Rev. B 2008, 77, 125215. doi:10.1103/PhysRevB.77.125215

73. Meyer, B. K.; Sann, J.; Lautenschläger, S.; Wagner, M. R.; Hoffmann, A. Phys. Rev. B 2007, 76, 184120. doi:10.1103/PhysRevB.76.184120

74. Wagner, M. R.; Callsen, G.; Reparaz, J. S.; Schulze, J.-H.; Kirste, R.; Cobet, M.; Ostapenko, I. A.; Rodt, S.; Nenstiel, C.; Kaiser, M.; Hoffmann, A.; Rodina, A. V.; Philipps, M. R.; Lautenschläger, S.; Eisermann, S.; Meyer, B. K. Phys. Rev. B 2011, 84, 035313. doi:10.1103/PhysRevB.84.035313

75. Kirste, R.; Mohn, S.; Wagner, M. R.; Reparaz, J. S.; Hoffmann, A. Appl. Phys. Lett. 2012, 101, 041909. doi:10.1063/1.4739415

76. Sahoo, S.; Sharma, G. L.; Katiyar, R. S. J. Raman Spectrosc. 2012, 43, 72. doi:10.1002/jrs.3004

77. Thakur, J. S.; Haddad, D.; Naik, V. M.; Naik, R.; Auner, G. W.; Lu, H.; Schaff, W. J. Phys. Rev. B 2005, 71, 115203. doi:10.1103/PhysRevB.71.115203

78. Demangeot, F.; Pinquier, C.; Frandon, J.; Gaio, M.; Briot, O.; Maleyre, B.; Ruffenach, S.; Gil, B. Phys. Rev. B 2005, 71, 104305. doi:10.1103/PhysRevB.71.104305

79. Reparaz, J. S.; Muniz, L. R.; Wagner, M. R.; Goñi, A. R.; Alonso, M. I.; Hoffmann, A.; Meyer, B. K. Appl. Phys. Lett. 2010, 96, 231906. doi:10.1063/1.3447798

80. Venkatesh, P. S.; Ramakrishnan, V.; Jeganathan, K. CrystEngComm 2012, 14, 3907. doi:10.1039/c2ce25220a

81. Diaz-Flores, L. L.; Ramírez-Bon, R.; Mendoza-Galván, A.; Prokhorov, E.; González-Hernández, J. J. Phys. Chem. Solids 2003, 64, 1037. doi:10.1016/S0022-3697(02)00476-6

82. Duvillaret, L.; Garet, F.; Coutaz, J.-L. Appl. Opt. 1999, 38, 409. doi:10.1364/AO.38.000409
83. Dorney, T. D.; Baraniuk, R. G.; Mittleman, D. M. J. Opt. Soc. Am. A 2001, 18, 1562. doi:10.1364/JOSAA.18.001562

84. Lloyd-Hughes, J.; Jeon, T.-I. J. Infrared, Millimeter, Terahertz Waves 2012, 33, 871. doi:10.1007/s10762-012-9905-y

85. Kužel, P.; Němec, H. J. Phys. D: Appl. Phys. 2014, 47, 374005. doi:10.1088/0022-3727/47/37/374005

\section{License and Terms}

This is an Open Access article under the terms of the Creative Commons Attribution License

(http://creativecommons.org/licenses/by/2.0), which permits unrestricted use, distribution, and reproduction in any medium, provided the original work is properly cited.

The license is subject to the Beilstein Journal of Nanotechnology terms and conditions:

(http://www.beilstein-journals.org/bjnano)

The definitive version of this article is the electronic one which can be found at: $\underline{\text { doi:10.3762/bjnano.6.222 }}$ 